\title{
More than one abortion
}

\section{Sam Rowlands}

\section{Introduction}

The terms 'repeat abortion' and 'repeat aborter' appear in the scientific literature from the early 1970 s onwards. To begin with, the pejorative term 'abortion recidivism' was used by some. 1 The initial concern appeared to be that women might be using abortion instead of contraception as a means of fertility control, with connotations of irresponsibility. $^{2-7}$ There were also concerns about risk of morbidity and mortality for the woman from complications, possible psychiatric sequelae and possible cumulative adverse effects on future reproductive outcome. $3,4,6$ The latter concerns are not dealt with in this paper but are fully addressed elsewhere in an evidencebased guideline. ${ }^{8}$

Women have been regarded as less deserving when they present for abortion with a history of having had a previous abortion. Doctors have felt "that to agree to a second abortion would only encourage immorality or at least carelessness". 9 In a recent survey, service providers were found to have discriminatory policies in their written approval criteria. One provider stated that "consultants are reluctant to undertake repeated terminations" and another that "if a doctor perceives that the patient regards termination of pregnancy as a form of contraception by virtue of the number of previous procedures had" then abortion will not be offered within the service contract. ${ }^{10}$ In some countries doctors have threatened women with sterilisation if they attend for subsequent abortions. ${ }^{11,12}$

In countries that have good access to legal abortion women will use safe abortion as an adjunct to contraception. Some methods of contraception are highly effective; but even when these methods are used, failures during typical use are substantial (eg, for the combined pill). ${ }^{13}$ It has been estimated that a fecund, sexually active woman relying only on abortion for fertility control would need to have 35 abortions during her lifetime if she wanted no children. ${ }^{14}$

This review starts by illustrating the phenomenon of so-called repeat abortion with statistics from several countries and proceeds to outline the demographic factors affecting trends over time. The review then summarises evidence of any differences between women having subsequent abortions and those having their first abortion. Finally, evidence is presented of any differences in contraceptive behaviour between the two groups. A literature search was conducted for the years 1966 to 2006 using the term 'repeat abortion' as a text word in MEDLINE, POPLINE, CINAHL and PsycINFO. Statistics were obtained from the following government websites: www.stakes.fi; www.dh.gov.uk/publichealthstatistics; www.sos.se; www.stats.govt.nz.

J Fam Plann Reprod Health Care 2007; 33(3): 155-158

(Accepted 31 January 2007)

Warwick Medical School, Warwick, UK

Sam Rowlands, MD, FRCGP, Honorary Senior Lecturer

Correspondence to: Dr Sam Rowlands, Warwick Medical School, Gibbet Hill Campus, University of Warwick, Coventry CV4 7AL, UK. E-mail: sam.rowlands@warwick.ac.uk

\section{Special category}

No strict definition of 'repeat' abortion was found. Mostly it seems that the term is used to describe more than one abortion ever. But is a second abortion 20 years after a first abortion really the same as a second abortion in the same year as a first in terms of its antecedents?

It is known that where a history of previous abortion is obtained by asking women, substantial underreporting occurs due to recall bias. ${ }^{15-17}$ Underreporting at interviews is likely to approach $100 \%$ in the early days of legalisation when the only experience is of illegal abortion; women are unlikely to admit to an illegal act. This means that data other than those from record linkage systems are unlikely to be reliable and constitute a considerable underestimate of the true number. It must also be recognised that some statistics report only previous legal abortions. Statistics from England and Wales and from New Zealand report only legal abortions in their own jurisdiction; statistics from the USA and Canada report without qualification.

Possible purposes of assigning women who have had one or more previous abortions a separate category might be as follows:

- Monitoring of secular trends in the proportions by statisticians

- Denial of further abortions by service providers after a certain number

- Targeting by health professionals to use a reliable method (preferably a long-acting method) of contraception in the future.

\section{Worldwide statistics}

In Hungary where abortion on request became available in 1956, the number of women with experience of abortion had almost stabilised by the early 1970s; so too had the proportion of these women having had more than one abortion, at around $57 \% .18$ In former Czechoslovakia where the law was liberalised in $1957,45 \%$ of married women undergoing abortion in 1982 had had a previous abortion. ${ }^{19}$ Canadian abortion statistics reveal the proportion of women having had a previous abortion increasing from $9 \%$ in 1975 to $29 \%$ in $1993 .{ }^{3}$ Data from the USA show an increase from $18 \%$ in 1975 to $42 \%$ in 1987.3 The latest USA data show that $47 \%$ of women undergoing abortion have had a previous abortion. ${ }^{20}$

Some countries are able to report on women having had previous abortions in their abortion statistics. Data for 2004/2005 show proportions of 32\% for Finland, $2136 \%$ for New Zealand 22 and $37 \%$ for Sweden. ${ }^{23}$ Two of these countries break their figures down further. In Finland and New Zealand $10 \%$ and $11 \%$, respectively, of women undergoing abortion had had more than one previous abortion. In Finland 3\% of women undergoing abortion had had more than two previous abortions. In Canada in 1993 , only $2 \%$ of abortions were obtained by women who had had more than two previous abortions, suggesting that abortion was not being widely used as a primary method of fertility control at that time. ${ }^{3}$ A study from Hawaii confirms this finding. 4 This is in contrast to former Eastern bloc countries where contraception was not freely available and women had large numbers of abortions: around six in a reproductive career in the former Soviet Union. ${ }^{24}$ 


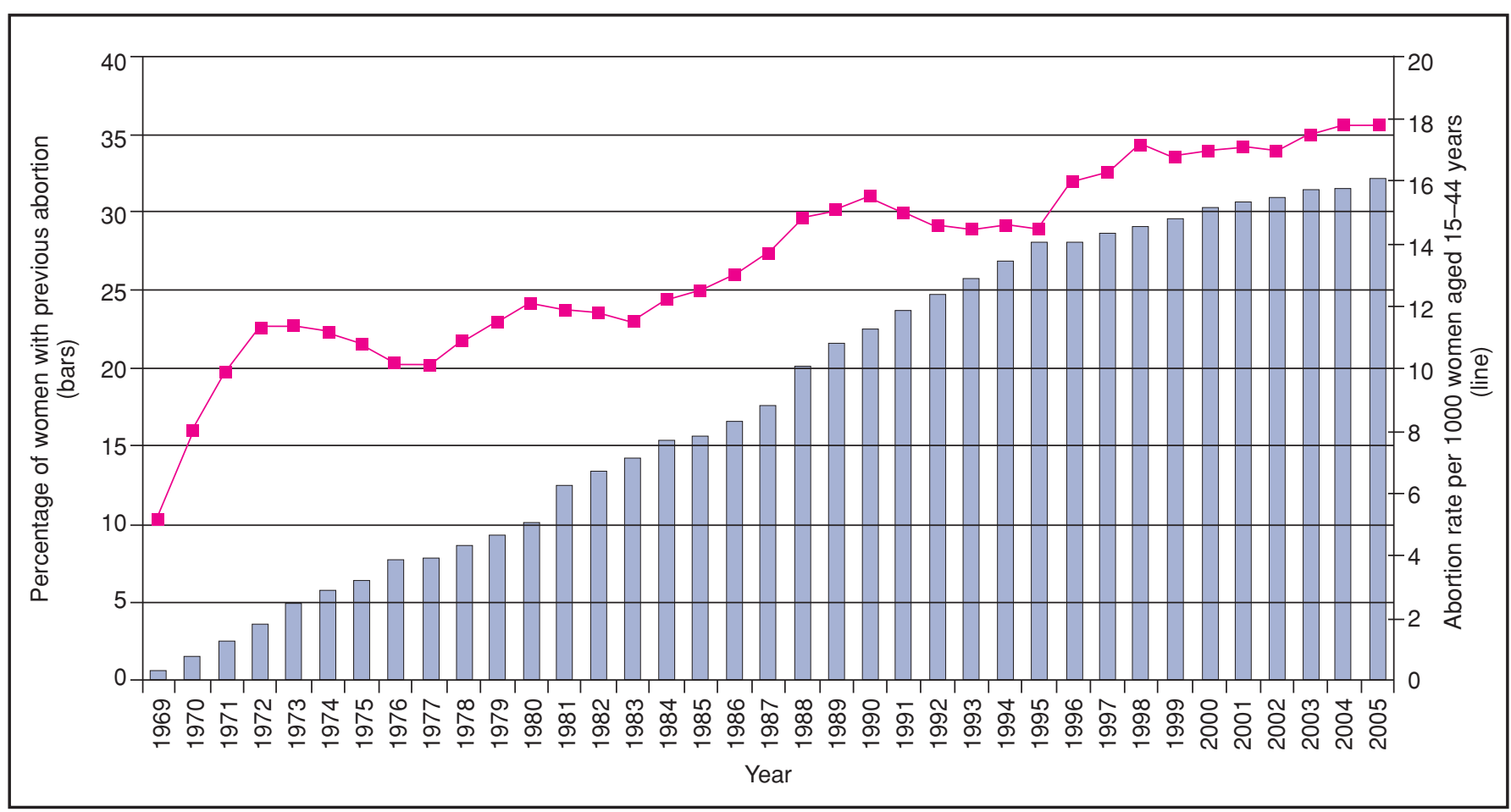

Figure 1 Annual proportion of residents undergoing abortion in England and Wales who had had a previous legal abortion shown with abortion rate. Sources: Office for National Statistics and Department of Health

\section{Epidemiology}

Tietze was the first to point out that for those women who have already experienced an abortion, a substantial proportion of those who use highly effective contraception will experience a subsequent unplanned pregnancy within a few years; many of these women will opt for another abortion. ${ }^{5}$ It has been shown in several countries where abortion is legal that an increase in the proportion of those having more than one abortion occurs over time..$^{6,25}$ So, increasing age (and parity) correlates with a greater chance of having more than one abortion. The population at risk of having more than one abortion expands. This is probably the main factor responsible for increasing proportions of women having more than one abortion in most countries. A steady state is reached around 30 years after legalisation of abortion. ${ }^{6}$ Also, the ultimate proportion of women having subsequent abortions rises with the level of the abortion rate. A woman who has had a previous abortion is more likely to have another abortion in a given year than a woman who has had no previous abortions is to have a first. 3,25 It is likely that women eligible for subsequent abortions are of higher fecundity than women potentially eligible for first abortions; some of the latter group will be infertile and some will not have so far reached their sexual debut.

\section{Statistics for England and Wales}

The proportion of English and Welsh women undergoing a subsequent legal abortion has risen from $0.7 \%$ in 196926 (the first complete year of legal abortion) to $32.3 \%$ in $2005^{27}$ (Figure 1). During this same time period, in England and Wales there was a rise in the age-standardised abortion rate per 1000 women aged 15-44 years from 5.2 in 1969 to 17.8 in 2005; the increase has been quite slight over the last 6 years ${ }^{28}$ (Figure 1). The latest annual England and Wales statistics 28 for the first time give figures for previous abortions in those aged under 25 years requesting abortion by primary care organisation. These range from 9\% in semi-rural Erewash, Derbyshire to $37 \%$ in inner city Kensington and Chelsea, London (average 24\%). It is not clear if these varying figures for under-25s reflect different types of population or whether improving contraception services would necessarily lower these proportions.

Data requested under the Freedom of Information Act for the first time give a breakdown of the number of previous abortions. ${ }^{27}$ Data for 2005 are shown in Table 1. The proportion of women having had one or more previous abortions was $32.3 \%$ for all ages, ranging from $8.0 \%$ in the under- 18 age group to $41.6 \%$ in the over-30 age group. The proportion of women having had three or more previous abortions was $2.2 \%$. Figures for England and Wales are similar to those for Finland, with a lower proportion of 'repeat' abortions than in New Zealand, Sweden and the USA.

\section{Comparative studies}

This is a complex area to study. The methodology used in studies is not always as rigorous as it could be. Also, the studies were performed in widely differing settings in terms of cultural attitudes and service provision.

Some studies show no differences between groups of women having first or subsequent abortions. ${ }^{29}$ Differences that have been shown in some studies are that compared to women having first abortions, women having subsequent abortions are more likely to:

- Present for abortion with less delay 30

- Have had an earlier sexual debut 31,32

- Have a higher coital frequency 18,33,34

- Have had a larger number of sexual partners 31

- Have had a sexually transmitted infection in the past ${ }^{34}$

- Have low socioeconomic status ${ }^{4,35-37}$

- Have suffered intimate partner (domestic) violence 34,38

- Be immigrants rather than natives of the country 39

- Have no religious affiliation. 40

It should be noted that some of the above differences have been shown in one study only so, without replication, the difference is not proven.

Psychosocial studies have shown a tendency for women who are undergoing subsequent abortions to have been neglected, to have had difficulties at school, conflicts with 
Table 1 Number (percentage) of previous abortions by selected age group, residents of England and Wales (2005) ${ }^{27}$

\begin{tabular}{lcrrr}
\hline $\begin{array}{l}\text { Previous } \\
\text { abortions }\end{array}$ & $\begin{array}{l}\text { Aged under } \\
\text { 18 years }\end{array}$ & $\begin{array}{l}\text { Aged over } \\
\text { 30 years }\end{array}$ & All ages \\
\hline 0 & $16558(92.0)$ & $28903(58.4)$ & $126228(67.7)$ \\
1 & $1316(7.3)$ & $14709(29.7)$ & $45423(24.4)$ \\
2 & $90(0.5)$ & $4148(8.4)$ & $10759(5.8)$ \\
3 & $*$ & $1128(2.3)$ & $2517(1.4)$ \\
4 & $*$ & $482(1.0)$ & $1233(0.7)$ \\
5 & $*$ & $92(0.2)$ & $162(0.09)$ \\
6 & $*$ & $29(0.06)$ & $50(0.03)$ \\
$7+$ & $18023(100)$ & $49515(100)$ & $186416(100)$ \\
Total & & $24(0.05)$ & $44(0.02)$ \\
\end{tabular}

${ }^{*}$ Suppressed data.

their current partner, and to be immature, dependent and impulsive individuals. ${ }^{41-43}$ They are more likely to have sexual problems too. 44

\section{Use of contraception}

Many studies have shown no lesser use of contraception in those undergoing subsequent abortions compared to women having first abortions.7,20,31,33,34,45-49 Several studies have shown that those having subsequent abortions had used contraception to a greater extent than women having first abortions. $7,20,33,34,45,48-50$ Two studies showed a greater use of coitus-independent contraceptive methods by women who had had previous abortions compared to women who had not. ${ }^{31,46}$ A single study showed that women who had had previous abortions were more consistent in their use of contraception than women who had not. ${ }^{48}$ Use of emergency contraception has been shown to be equally poor in both groups. 49

Women of lower socioeconomic status are less likely to use highly effective contraception after abortion. ${ }^{51}$ A postabortion contraception intervention reduces subsequent abortions compared to receipt of no contraceptive advice at all. ${ }^{52}$ Specialist contraceptive counselling and enhanced provision compared to standard care has been shown in a randomised controlled trial to improve uptake of longacting reversible contraception; however, the intervention had no effect on the likelihood of a woman returning for another abortion within a time period of 2 years. ${ }^{53}$

Complex psychological conflicts may be a potent cause of non-use of contraception.54 Psychological factors that affect use of contraception include: 55

- Self-esteem

- Personality

- Interpersonal skills (including negotiation)

- Relationship status

- Peer influences

- Attitudes to sex and contraception

- Experience of sex, contraception and pregnancy

- Sex education received

- Gender/power issues

- Substance abuse prior to sex.

There is an association between substance abuse and abortion. One study found that women who are less conventional in their attitudes and behaviour are more likely to engage in risky behaviours, including use of cannabis and hard drugs, that put them at risk of unplanned pregnancy. 56

\section{Conclusions}

It does not appear that women in the West use abortion alone as a means of fertility control. We now understand better that women have abortions regardless of the legal situation in their country. ${ }^{57,58}$ It is much safer for a woman to have an abortion in proper conditions than it is to be sent away. We never want to go back to clandestine abortions and the resultant morbidity and mortality from sepsis, air/fluid embolism, mechanical trauma and chemical burns. 59,60

Every woman requesting abortion should be treated according to her individual circumstances. Categorising women by how many previous abortions they have had is both unscientific and inhumane. It is also judgmental, rather like putting a limit on the number of times emergency hormonal contraception is prescribed. ${ }^{61}$ Despite the fact that no reports were found of women feeling stigmatised, labels such as 'recidivist', 'habitual aborter' and 'repeater' to describe women have no place in modern society.

There is no valid reason why women presenting for abortion who have had a previous abortion should be treated any differently from those who have not. All women requesting abortion should receive information and support; in addition, some will require counselling. ${ }^{62}$ All women requesting abortion should be offered prophylaxis against pelvic infection and ideally screening for sexually transmitted infections. 8 As all women seeking abortion, regardless of previous abortion history, are at higher risk of intimate partner violence, 38,63-67 health professionals assessing such women should have an awareness of such an association and liaise with professional colleagues if there are concerns. Sometimes an abusing male is the escort.

All women potentially have contraceptive needs and these should be met around the time of an abortion just as they should be at any other time. Peri-abortion contraceptive counselling is important for all women; this should include offering and being able to provide long-acting reversible contraception. ${ }^{68}$ Service providers in different health sectors should work to jointly agreed care pathways.

Improving access to contraception is an essential first step. ${ }^{69}$ Promotion of sexual health is also required; this is more challenging but can be done. ${ }^{70}$ Making long-acting reversible contraception more widely available is likely to have a general beneficial effect on unintended pregnancy rates. Provision of emergency contraception in advance ${ }^{71}$ may also facilitate use of emergency hormonal contraception. Future research should focus on further psychological factors for a whole population that detract from consistent use of contraception; from these possible effective interventions can be developed.

\section{Acknowledgment}

The author would like to thank the anonymous reviewer for helpful comments that significantly improved the paper.

Statements on funding and competing interests

Funding None identified.

Competing interests None identified.

References

1 Rovinsky JJ. Abortion recidivism: a problem in preventive medicine. Obstet Gynecol 1972; 39: 649-659.

2 Tietze C. Repeat abortions - why more? Fam Plann Perspect 1978; 10: 286-288.

3 Millar WJ, Wadhera S, Henshaw SK. Repeat abortions in Canada, 1975-1993. Fam Plann Perspect 1997; 29: 20-24.

4 Steinhoff PG, Smith RG, Palmore JA, Diamond M, Chung CS. Women who obtain repeat abortions: a study based on record linkage. Fam Plann Perpsect 1979; 11: 30-38.

5 Tietze C. The 'problem' of repeat abortions. Fam Plann Perspect 1974; 6: 148-150.

6 Tietze C, Bongaarts J. Repeat abortion in the United States: new insights. Stud Fam Plann 1982; 13: 373-379.

7 Bracken MB, Hachamovitch M, Grossman G. Correlates of repeat induced abortions. Obstet Gynecol 1972; 40: 816-825.

8 Royal College of Obstetricians and Gynaecologists. The Care of Women Requesting Induced Abortion (National Evidence-Based Clinical Guideline No. 7) (2nd edn). London, UK: RCOG Press, 2004.

9 Aitken-Swan J. Epidemiological background. In: Horrobin G (ed.), Experience with Abortion: A Case Study of North-East Scotland. Cambridge, UK: Cambridge University Press, 1973. 
10 Roe J. NHS Abortion Services, a Survey of Primary Care Trusts by the All-Party Parliamentary Pro-Choice \& Sexual Health Group. London, UK: Voice for Choice, 2004.

11 Wolf B. Repeat abortion: utilisation and social influences [in German]. Zentralb/ Gynakol 1991; 113: 21-28.

12 Neamatalla GS, Verme CS. Postabortion Women: Influencing Their Family Planning Options (AVSC Working Paper No. 9). New York, NY: EngenderHealth (previously AVSC International), 1995.

13 Trussell J. Contraceptive failure in the United States. Contraception 2004; 70: 89-96.

14 Harlap S, Kost K, Forrest JD. Preventing Pregnancy, Protecting Health: A New Look at Birth Control in the United States. New York, NY: Alan Guttmacher Institute, 1991.

15 Udry JR, Gaughan M, Schwingl PJ, van den Berg BJ. A medical record linkage analysis of abortion underreporting. Fam Plann Perspect 1996; 28: 228-231.

16 Tang MT, Weiss NJ, Daling JR, Malone M. Case control differences in the reliability of reporting a history of induced abortion. Am J Epidemiol 2000; 15: 1144-1147.

17 Jagannathan R. Relying on surveys to understand abortion behaviour: some cautionary evidence. Am J Public Health 2001; 91: 1825-1831.

18 Tietze C. Induced Abortion: 1979 (3rd edn). New York, NY: Population Council, 1979.

19 Ŝráĉek J. Czechoslovakia. In: Sachdev P (ed.), International Handbook on Abortion. New York, NY: Greenwood Press, 1988; 127-137.

20 Jones RK, Singh S, Finer LB, Frohwirth LF. Repeat Abortion in the United States (Occasional Report No. 29). New York, NY: Guttmacher Institute, 2006.

21 Induced Abortions and Sterilisations in 2004. Helsinki, Finland: STAKES (National Research and Development Centre for Welfare and Health), 2005.

22 Bascand G. Abortions Year Ended December 2005. Wellington, New Zealand: Statistics New Zealand, 2006.

23 Abortions 2005. Stockholm, Sweden: Socialstyrelsen (National Board of Health and Welfare), 2006.

24 Popov A. Family planning and induced abortion in the USSR: basic health and demographic characteristics. Stud Fam Plann 1991; 22: 368-377.

25 Skjeldestad FE, Bakketeig LS. Induced abortion: trends in the tendency to repeat, Norway, 1972-1981. Scand J Soc Med 1986; 14: 205-209.

26 Abortion Statistics, England \& Wales: 1969. London, UK: Office of Population Censuses and Surveys, 1971.

27 Abortion: Numbers of Previous Abortions by Age Group. London, UK: Department of Health, 2006.

28 Abortion Statistics, England \& Wales: 2005. London, UK: Department of Health, 2006.

29 Osler M, David HP, Morgall JM. Multiple induced abortions: Danish experience. Patient Educ Couns 1997; 31: 83-89.

30 Bracken MB, Kasl SV. First and repeat abortions: a study of decision-making and delay. J Biosoc Sci 1975; 7: 473-491.

31 Jacobsson L, von Schoultz B, Solheim F. Repeat aborters - first aborters, a social-psychiatric comparison. Soc Psychiatry Psychiatr Epidemiol 1976; 11: 75-86

32 Tsoi WF, Tay GE, Ratnam SS. Psychosocial characteristics of repeat aborters in Singapore. Biol Soc 1987; 4: 78-84.

33 Howe B, Kaplan HR, English C. Repeat abortions: blaming the victims. Am J Public Health 1979; 69: 1242-1246.

34 Fisher WA, Singh SS, Shuper PA, Carey M, Otchet F, MacLeanBrine D, et al. Characteristics of women undergoing repeat induced abortion. CMAJ 2005; 172: 637-641.

35 Freeman EW, Rickels K, Huggins GR, Garcia C-R, Polin J. Emotional distress patterns among women having first or repeat abortions. Obstet Gynecol 1980; 55: 630-636.

36 Hamark B, Uddenberg N, Forssman L. The influence of social class on parity and psychological reactions in women coming for induced abortion. Acta Obstet Gynecol Scand 1995; 74 302-306.

37 St John H, Critchley H, Glasier A. Can we identify women at risk of more than one termination of pregnancy? Contraception 2005; 71: 31-34

$38 \mathrm{Wu}$ J, Guo S, Qu C. Domestic violence against women seeking induced abortion in China. Contraception 2005; 72: 117-121.

39 Helström L, Odlind V, Zätterström C, Johansson M, Granath F, Correia $\mathrm{N}$, et al. Abortion rate and contraceptive practices in immigrant and native women in Sweden. Scand J Public Health 2003; 31: 405-410.

40 Leach J. The repeat abortion patient. Fam Plann Perspect 1977; 9: 37-39.

41 Mattauer B, Peyrot D, Aussilloux MT. A study of repeated requests for induced abortions [in French]. Ann Med Psychol (Paris) 1984; 142: $151-163$

42 Rossi N, Bassi L, Delfino MD. Induced abortion and the problem of repeat abortions: a psychosocial study [in Italian]. Arch Psicol Neurol Psichiatr 1988; 49: 429-450.
43 Törnbom M, Ingelhammar E, Lilja H, Möller A, Svanberg B. Repeat abortion: a comparative study. J Psychosom Obstet Gynecol 1996; 17: 208-214.

44 Törnbom M, Möller A. Repeat abortion: a qualitative study. J Psychosom Obstet Gynecol 1999; 20: 21-30.

45 Daily EF, Nicholas N, Nelson F, Pakter J. Repeat abortions in New York City: 1970-1972. Fam Plann Perspect 1973; 5: 89-93.

46 Callan VJ. Repeat and first abortion seekers: single women in Brisbane, Australia. J Biosoc Sci 1983; 15: 217-222.

47 Holmgren K. Repeat abortion and contraceptive use: report from an interview study in Stockholm. Gynecol Obstet Invest 1994; 37: 254-259.

48 Westfall JM, Kallail KJ. Repeat abortion and use of primary health services. Fam Plann Perspect 1995; 27: 162-165.

49 Garg M, Singh M, Mansour D. Peri-abortion contraceptive care: can we reduce the incidence of repeat abortions? J Fam Plann Reprod Health Care 2001; 27: 77-88.

50 Bianchi-Demicheli F, Perrin E, Bianchi PG, Dumont P, Lüdicke F, Campana A. Contraceptive practice before and after termination of pregnancy: a prospective study. Contraception 2003; 67 . 107-113.

51 Bajos N, Lamarche-Vadel A, Gilbert F, Ferrand M. Contraception at the time of abortion: high-risk time or high-risk women? Hum Reprod 2006; 21: 2862-2867.

52 Johnson BR, Ndhlovu S, Farr SL, Chipato T. Reducing unplanned pregnancy and abortion in Zimbabwe through postabortion contraception. Stud Fam Plann 2002; 33: 195-202.

53 Schunmann C, Glasier A. specialist contraceptive counselling and provision after termination of pregnancy improves uptake of long-acting methods but does not prevent repeat abortion: a randomized trial. Hum Reprod 2006; 21: 2296-2303.

54 Blumenfield M. Psychological factors involved in request for elective abortions. J Clin Psychiatry 1978; 39: 17-25.

55 Ogden J. Health Psychology: A Textbook (3rd edn). Buckingham, UK: Open University Press, 2004.

56 Martino SC, Collins RL, Ellickson PL, Klein DJ. Exploring the link between substance use and abortion: the roles of unconventionality and unplanned pregnancy. Perspect Sex Reprod Health 2006; 38: 66-75.

57 David HP. Abortion policies. In: Hodgson JE (ed.), Abortion and Sterilization: Medical and Social Aspects. London, UK: Academic Press, 1981 ; 1-40.

58 Van Look PFA, von Hertzen H. Induced abortion: a global perspective. In: Baird DT, Grimes DA, Van Look PFA (eds) Modern Methods of Inducing Abortion. Oxford, UK: Blackwell Science, 1995; 1-24.

59 Parish TN. A thousand cases of abortion. J Obstet Gynaecol Br Emp 1935; 42: 1107-1121.

60 Davis A. 2,665 cases of abortion: a clinical survey. BMJ 1950; 2: 123-130.

61 Ziebland S, Graham A, McPherson A. Concerns and cautions about prescribing and deregulating emergency contraception: a qualitative study of GPs using telephone interviews. Fam Pract 1998; 15: 449-456.

62 Brien J, Fairbairn I. Pregnancy and Abortion Counselling. London, UK: Routledge, 1996.

63 Evins G, Chescheir N. Prevalence of domestic violence among women seeking abortion services. Womens Health Issues 1996; 6: 204-210

64 Glander SS, Moore ML, Michielutte R, Parsons LH. The prevalence of domestic violence among women seeking abortion. Obstet Gynecol 1998; 91: 1002-1006.

65 Russo N, Denious J. Violence in the lives of women having abortions: implications for practice and public policy. Prof Psychol Res Pr 2001; 32: 142-150.

66 Leung TW, Leung WC, Chan PL, Ho PC. A comparison of the prevalence of domestic violence between patients seeking termination of pregnancy and other general gynaecology patients. Int J Gynecol Obstet 2002; 77: 47-54.

67 Keeling J, Birch L, Green P. Pregnancy counselling clinic: a questionnaire survey of intimate partner abuse. J Fam Plann Reprod Health Care 2004; 30: 165-168.

68 National Institute for Health and Clinical Excellence (NICE). Long-acting Reversible Contraception (NICE Clinical Guideline 30). London, UK: NICE, 2005

69 Medical Foundation for AIDS and Sexual Health Project Advisory Group. Access to Services. Recommended Standards for Sexual Health Services. London, UK: Department of Health, 2005; 47-53.

70 Medical Foundation for AIDS and Sexual Health Project Advisory Group. Promoting Sexual Health. Recommended Standards for Sexual Health Services. London, UK: Department of Health, 2005; 26-32.

71 Jackson RA, Bimla Schwarz E, Freedman L, Darney P. Advance supply of emergency contraception: effect on use and usual contraception - a randomized trial. Obstet Gynecol 2003; 102: 8-16. 